\title{
Expression of Vascular endothelial growth factor in Ewing's sarcoma
}

\author{
Ramakant Kumar • Sukesh Sankineani • \\ Shishir Rastogi • Shyam Prakash • Sameer Bakhshi • \\ Mehar C. Sharma • Shahalam Khan • Gopal Sagar DC • \\ Laxman Rijal
}

Received: 21 February 2012 / Accepted: 23 April 2012 / Published online: 29 May 2012

(C) Springer-Verlag 2012

\begin{abstract}
Purpose Vascular endothelial growth factor (VEGF) is the most potent stimulator of angiogenesis. The aim of this study was to evaluate the role of serum VEGF as a diagnostic, predictive and prognostic marker in Ewing's sarcoma.

Methods Patients with histopathologically proven diagnosis of Ewing's sarcoma without prior chemotherapy or radiotherapy were invited to take part in the study. Prechemotherapy, post-chemotherapy and post-surgery blood samples were collected for analysis of serum VEGF levels. Blood samples from ten sex- and age-matched healthy volunteers were collected for estimation of VEGF levels to act as control. Human VEGF Elisa kit (Bender Medsystem, Austria) was used to assess the serum VEGF levels.

Results A total of nine cases of Ewing's sarcoma were included in the study. Mean age in the group was 12.44 years (range, seven to 18 years). Mean and median serums VEGF level in the study population were $4,547.78 \mathrm{pg} / \mathrm{ml}$ and $3,780.00 \mathrm{pg} / \mathrm{ml}$,
\end{abstract}

R. Kumar $(\bowtie) \cdot$ S. Sankineani $\cdot$ S. Rastogi $\cdot$ S. Khan $\cdot$

G. Sagar DC $\cdot$ L. Rijal

Orthopaedics, AIIMS,

New Delhi, India

e-mail: ramakantaiims2007@gmail.com

S. Prakash

Human Nutrition Unit Lab, Department of Gastroenterology,

AIIMS,

New Delhi, India

\section{S. Bakhshi}

Medical Oncology, BRAIRCH, AIIMS,

New Delhi, India

M. C. Sharma

Pathology, AIIMS,

New Delhi, India respectively. Ten age- and sex-matched healthy volunteers were selected as controls. No significant correlation was obtained between serum VEGF, age, sex and tumour size. Mean serum VEGF was significantly raised in the study group as compared to controls $(p=0.001$ ). We observed a significant decline in serum VEGF level following neoadjuvant chemotherapy $(p=0.008)$. No correlation could be established between serum VEGF level pulmonary metastasis and overall survival.

Conclusion Serum VEGF might have a role as a diagnostic and predictive marker in patients with Ewing's sarcoma.

\section{Introduction}

Ewing's sarcoma is a primitive neuroectodermal tumour that most often affects children and young adults in the first two decades of life. It is the second most common malignant bone tumour in children and accounts for $10-15 \%$ of all primary bone tumours. It is an aggressive tumour whose prognosis is critically determined by the adequacy of the local control of the primary lesion and by the efficacy of the systemic chemotherapy treatment aimed at the control of micro metastatic disease $[1,2]$. Therefore identification of prognostic markers is considered to be of major importance in the development of new strategies of treatment. Angiogenesis is essential for the growth of a tumour and its metastases [3]. Vascular endothelial growth factor (VEGF) is the most potent stimulator of angiogenesis [4]. It is a major angiogenic factor that induces endothelial cell proliferation and increases the permeability of the vascular endothelium [5]. Activation of the VEGFreceptor pathway triggers a network of signalling processes that promotes endothelial cell growth, migration, and survival from pre-existing vasculature. Tissue expression of VEGF correlates well with tumour progression and has been shown 
to be of prognostic significance in many malignancies [6-12]. Measurement of serum VEGF levels by ELISA appears to be a more promising procedure for quantification than immunohistochemical staining of tissue VEGF [13]. The aim of this study was to evaluate the role of VEGF as a diagnostic, predictive and prognostic marker in Ewing's sarcoma.

\section{Materials and methods}

The prospective study was conducted in the Department of Orthopaedics of a tertiary care referral centre from November 2007 to November 2009 after approval by the institutional ethics committee. Patients with histopathologically proven diagnosis of Ewing's sarcoma without prior chemotherapy or radiotherapy were invited to take part in the study after written informed consent. Patients with secondary malignancies, prior chemo/radiotherapy or surgery for the malignancy, patients with pulmonary or non pulmonary distant metastasis at presentation and those aged less than two years and more than 75 years, were excluded from the study. All patients were managed according to the standardised treatment protocol consisting of neo adjuvant chemotherapy consisting of Vincristine, Actinomycin-D and Cyclophosphamide administered in alternate cycles with Etoposide and Ifosfamide. A total of 17 cycles of chemotherapy were given at an interval of three weeks, spread over a period of 48 weeks, followed by appropriate surgical management and postoperative adjuvant chemotherapy. Prechemotherapy, post-chemotherapy and post-surgery blood samples $(5 \mathrm{ml})$ were collected for analysis of serum VEGF levels. Blood samples from ten sex- and age-matched healthy volunteers were collected for estimation of VEGF levels to act as control. If there was a delay in measuring the VEGF levels then the serum was separated and was stored at $-20{ }^{\circ} \mathrm{C}$ to avoid loss of bioactive serum VEGF. Human VEGF Elisa kit (Bender Medsystem, Austria) was used to assess the serum VEGF levels. The volume of primary tumour was assessed from longitudinal and transverse images of magnetic resonance imaging that had been taken before biopsy, and calculated with the formula: $\pi / 6 \times$ height $\times$ width $\times$ depth [4].

\section{Statistical analyses}

Statistical analyses were performed using SPSS 17 software. The Mann-Whitney U test was used to compare serum concentrations of patients with those of the control group. Correlation was analysed by Pearson's correlation test. Matchedpaired samples (pre-therapeutic and post-therapeutic) were analysed with the Wilcoxon matched pairs signed-rank test.

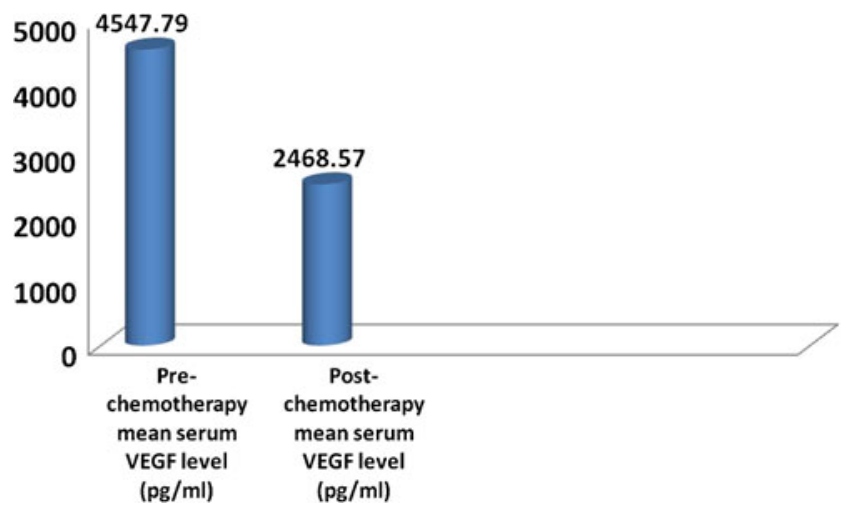

Fig. 1 Showing decline in serum vascular endothelial growth factor (VEGF) level following chemotherapy $(p=0.008)$. $Y$-axis mean serum VEGF level (pg/ml)

Kaplan-Meier curves for overall survival and disease free survival were analysed by log rank test.

\section{Results}

From November 2007-2009, a total of nine patients with the histopathological diagnosis of Ewing's sarcoma were included in the study with four female and five male patients. Mean age in the group was 12.44 years (range, seven to 18 years). Femur was the most common bone involved followed by tibia and humerus. One case of Ewing's sarcoma of clavicle was also reported. A total of four patients developed pulmonary metastasis and one patient succumbed to the disease, over a follow-up period ranging from eight to 24 months with a mean of 12 months. Mean and median serums VEGF levels in the study population were $4,547.78 \mathrm{pg} / \mathrm{ml}$ and $3,780.00 \mathrm{pg} / \mathrm{ml}$, respectively. Ten healthy volunteers (mean age 14.28 years, mean serum VEGF level $607.8 \mathrm{pg} / \mathrm{ml}$ ) were selected as controls.

Association between VEGF and different clinico-pathological variables

No significant association was observed between serum level of VEGF and age, sex and tumour volume and pulmonary metastasis. Mean serum VEGF level was

Table 1 Survival and vascular endothelial growth factor (VEGF) level

\begin{tabular}{lllll}
\hline $\begin{array}{l}\text { Serum } \\
\text { VEGF level }\end{array}$ & $\begin{array}{l}\text { Total } \\
\text { number }\end{array}$ & Death & $\begin{array}{l}\text { Overall survival } \\
\text { at one year }\end{array}$ & $\begin{array}{l}\text { P value } \\
\text { (log rank) }\end{array}$ \\
\hline$>4000 \mathrm{pg} / \mathrm{ml}$ & 4 & 0 & $100 \%$ & 0.414 \\
$<4000 \mathrm{pg} / \mathrm{ml}$ & 5 & 1 & $80 \%$ & \\
\hline
\end{tabular}


significantly higher in patients with Ewing's sarcoma as compared to controls $(p=0.001)$.

Serum VEGF level following therapeutic intervention

Serum VEGF level was measured following 17 cycles of chemotherapy. Post-chemotherapy serum VEGF level was correlated with its level obtained in the serum before chemotherapy. The decline in mean serum VEGF level following chemotherapy was statistically significant $(p=0.008)$ (Fig. 1).

Overall survival in Ewing's sarcoma patients in relation to various clinico pathological variables

A total of nine cases of Ewing's sarcoma were included in the study. Out of nine cases, four developed pulmonary metastasis (one patient succumbed to the disease). Overall survival in patients with metastasis was $75 \%$ and in the non metastasis group $100 \%$. Survival at one year in the metastasis group was $66.7 \%$. Overall survival as a function of age was $88.9 \%$. We also tried to correlate serum VEGF level and survival. We chose the cut-off value of $4,000 \mathrm{pg} / \mathrm{ml}$ to compare the survival. This value was chosen because mean serum VEGF level in the patients with pulmonary metastasis was 4,075.89 $\mathrm{pg} / \mathrm{ml}$, which is an independent factor for survival (Table 1). No Kaplan-Meier plot could be drawn because end event (death) occurred only in one group with serum level less than $4,000 \mathrm{pg} / \mathrm{ml}$.

\section{Discussion}

In malignant lesions there is growth of new blood vessels. Many investigations have revealed the key molecule in the regulation of new vessel formation is vascular endothelial growth factor (VEGF) — an endothelial-cell-specific mitogen and survival factor. VEGF causes increased vascular permeability and recruits progenitor endothelial cells from the bone marrow. Clinical observations have confirmed that VEGF status is closely associated with the extent of neovascularisation and prognosis in many solid tumours. Most of the earlier available studies for VEGF expression were based on immunohistochemical analysis in the biopsied tissue of Ewing's sarcoma patients. In this study serum level of VEGF was measured. Measurement of serum VEGF level is advantageous for its simple and rapid procedure and provides a prognostic value consistent with immunohistochemical [14] and genetic detection [5] of tissue VEGF in biopsy specimens. Helena et al. [15] studied the role of VEGF and basic fibroblast factor (bFGF) in various paediatric solid malignancies using enzyme linked immunosorbent assay (ELISA). Serum and urinary levels of VEGF and bFGF were measured in both the cases and healthy controls.
They did not find any correlation between serum VEGF, age, sex and tumour volume. Interestingly, serum VEGF level was significantly elevated in the primitive neuroectodermal group of tumours and in patients with lymphoma. In 16 patients who underwent remission following chemotherapy, they compared serum VEGF and bFGF levels before and after chemotherapy and found significant decline in VEGF, but serum bFGF level was unaffected. However, they did not mention in which histological group of paediatric solid malignancies this decline in serum VEGF level occurred. Diagnostic values of urinary VEGF and bFGF because of easy access of the urine samples were also studied, but no differences between cases and control were found. We also agree with the explanation of Helena et al. that tumour tissues are the main source of VEGF (platelet only act as a transport), as we also did not find any difference in the platelet count pre and post-chemotherapy (data not included). In this study we also did not find any correlation between serum VEGF level, age, and sex and tumour volume. Serum VEGF level was significantly raised in the patients as compared to controls $(p=0.001)$. Post chemotherapy serum VEGF level was also compared to the pre chemotherapy serum VEGF level to look for its potential role as a predictive marker. We found a significant fall in serum VEGF level following ( $p=0.008)$ chemotherapy, suggesting VEGF might play a role in monitoring response to chemotherapy. Similar findings have been reported by several other authors [16, 17]. Four patients developed pulmonary metastasis during follow-up, but we did not find any correlation between serum VEGF level and development of pulmonary metastasis and overall survival, although a similar finding was reported by Rutkowski et al. [17]. El-Houseini et al. [18] concluded that angiogenesis is essential for solid tumour growth and demonstrated significantly higher serum VEGF level in Ewing's sarcoma patients as compared to controls, but similar to Helena et al. [15] did not find any correlation between serum VEGF and age, sex and tumour size. Several authors [19-21] have linked VEGF as an independent factor of survival in Ewing's sarcoma. Zhou et al. [22] showed that bone marrow cells participate in new tumour vessel formation in Ewing's sarcoma, and that vascular endothelial growth factor is critical to this process and indicated that blocking VEGF-receptor with antibodies may be a useful therapeutic approach for treating patients with Ewing's sarcoma.

\section{Conclusions}

VEGF might play a role as diagnostic and predictive marker; however, further studies with greater sample size are needed to support the hypothesis. 


\section{References}

1. West DC (2000) Ewing sarcoma family of tumors. Curr Opin Oncol 12(4):323-329

2. de Alava E, Gerald WL (2000) Molecular biology of the Ewing's sarcoma/primitive neuroectodermal tumor family. J Clin Oncol 18 (1):204-213

3. Folkman J (1995) Seminars in Medicine of the Beth Israel Hospital, Boston. Clinical applications of research on angiogenesis. N Engl J Med 333(26):1757-1763

4. Kaya M, Wada T, Nagoya S, Sasaki M, Matsumura T, Yamashita T (2009) The level of vascular endothelial growth factor as a predictor of a poor prognosis in osteosarcoma. J Bone Joint Surg Br 91 (6):784-788

5. Lee YH, Tokunaga T, Oshika Y, Suto R, Yanagisawa K, Tomisawa $M$ et al (1999) Cell-retained isoforms of vascular endothelial growth factor (VEGF) are correlated with poor prognosis in osteosarcoma. Eur J Cancer 35(7):1089-1093

6. Karayiannakis AJ, Syrigos KN, Polychronidis A, Zbar A, Kouraklis G, Simopoulos C et al (2002) Circulating VEGF levels in the serum of gastric cancer patients: correlation with pathological variables, patient survival, and tumor surgery. Ann Surg 236(1):37-42

7. Poon RT, Fan ST, Wong J (2001) Clinical implications of circulating angiogenic factors in cancer patients. J Clin Oncol 19(4):1207-1225

8. Teknos TN, Cox C, Yoo S, Chepeha DB, Wolf GT, Bradford CR et al (2002) Elevated serum vascular endothelial growth factor and decreased survival in advanced laryngeal carcinoma. Head Neck 24(11):1004-1011

9. Miyake H, Hara I, Yamanaka K, Gohji K, Arakawa S, Kamidono S (1999) Elevation of serum level of vascular endothelial growth factor as a new predictor of recurrence and disease progression in patients with superficial urothelial cancer. Urology 53(2):302-307

10. Cooper BC, Ritchie JM, Broghammer CLW, Coffin J, Sorosky JI, Buller RE et al (2002) Preoperative serum vascular endothelial growth factor levels: significance in ovarian cancer. Clin Cancer Res 8(10):3193-3197

11. Werther K, Christensen IJ, Nielsen HJ (2002) Prognostic impact of matched preoperative plasma and serum VEGF in patients with primary colorectal carcinoma. Br J Cancer 86(3):417-423

12. Poon RTP, Ho JWY, Tong CSW, Lau C, Ng IOL, Fan S-T (2004) Prognostic significance of serum vascular endothelial growth factor and endostatin in patients with hepatocellular carcinoma. Br J Surg 91(10):1354-1360

13. Kaya M, Wada T, Kawaguchi S, Nagoya S, Yamashita T, Abe Y et al (2002) Increased pre-therapeutic serum vascular endothelial growth factor in patients with early clinical relapse of osteosarcoma. Br J Cancer 86(6):864-869

14. Kaya M, Wada T, Akatsuka T, Kawaguchi S, Nagoya S, Shindoh $M$ et al (2000) Vascular endothelial growth factor expression in untreated osteosarcoma is predictive of pulmonary metastasis and poor prognosis. Clin Cancer Res 6(2):572-577

15. Pavlakovic H, Von Schütz V, Rössler J, Koscielniak E, Havers W, Schweigerer L (2001) Quantification of angiogenesis stimulators in children with solid malignancies. Int $\mathrm{J}$ Cancer 92 (5):756-760

16. Holzer G, Obermair A, Koschat M, Preyer O, Kotz R, Trieb K (2001) Concentration of vascular endothelial growth factor (VEGF) in the serum of patients with malignant bone tumors. Med Pediatr Oncol 36(6):601-604

17. Rutkowski P, Kamińska J, Kowalska M, Ruka W, Steffen J (2003) Cytokine and cytokine receptor serum levels in adult bone sarcoma patients: correlations with local tumor extent and prognosis. J Surg Oncol 84(3):151-159

18. El-Houseini ME, Abdel-Azim SA-F, El-Desouky GI, Abdel-Hady S, El-Hamad MF, Kamel AM (2004) Clinical significance of vascular endothelial growth factor (VEGF) in sera of patients with pediatric malignancies. J Egypt Natl Canc Inst 16(1):57-61

19. Fuchs B, Inwards CY, Janknecht R (2004) Vascular endothelial growth factor expression is up-regulated by EWS-ETS oncoproteins and Sp1 and may represent an independent predictor of survival in Ewing's sarcoma. Clin Cancer Res 10(4):1344-1353

20. Dalal S, Berry AM, Cullinane CJ, Mangham DC, Grimer R, Lewis IJ et al (2005) Vascular endothelial growth factor: a therapeutic target for tumors of the Ewing's sarcoma family. Clin Cancer Res 11(6):2364-2378

21. Kreuter M, Paulussen M, Boeckeler J, Gerss J, Buerger H, Liebscher $\mathrm{C}$ et al (2006) Clinical significance of vascular endothelial growth factor-A expression in Ewing's sarcoma. Eur J Cancer 42(12):1904-1911

22. Zhou Z, Reddy K, Guan H, Kleinerman ES (2007) VEGF(165), but not VEGF(189), stimulates vasculogenesis and bone marrow cell migration into Ewing's sarcoma tumors in vivo. Mol Cancer Res 5(11):1125-1132 